UDC 316.351

LBC 60.5

\title{
STUDY ON THE FEATURES OF PROFESSIONAL SELF-DETERMINATION OF THE GIFTED YOUTH (ON THE EXAMPLE OF THE WORKING YOUTH OF THE TYUMEN REGION) ${ }^{1}$
}

\author{
Lyudmila V. Gulyaeva \\ Tyumen State University, Tyumen, Russian Federation \\ Galina Z. Efimova \\ Tyumen State University, Tyumen, Russian Federation
}

\begin{abstract}
The gifted youth are a strategic intellectual resource for the development of all countries in the long term. The priority direction of activity concerning the formation of creative potential of the gifted youth representatives is the creation of conditions for the actualization of their creative abilities and interests in the course of their professional determination.

The purpose of this theoretical and applied research is to study the factors affecting the professional selfdetermination of representatives of gifted youth, as well as to identify the most significant features of this process.

The authors analyzed the results of theoretical works of domestic and foreign researchers; they studied official statistical data. As the methodological basis of their research the authors suggest a questionnaire survey of 956 representatives of the working youth, conducted in 2017 in the cities of Tyumen, Tobolsk, Ishim. The licensed version of IBM SPSS Statistics 23 was used to analyze empirical data.

Investigating the issue the researchers found out that the presence of young people with high abilities in any field during training at school and institutions of the secondary vocational and higher education contributes to the choice of their work on the profile of education in future, as well as a higher assessment of their personal and competitive potential, professional competence. At the same time, respondents from this group express great interest in moving to another country, despite concerns about the future of Russia. The authors confirm the assumption, that respondents have higher abilities in a certain area contributes to a more active process of their professional self-determination, greater stability and depth of their professional interests in the chosen field of activity.
\end{abstract}

The results obtained in the course of the study may be useful for teachers and psychologists engaged in career guidance activities in the framework of work with gifted children and adolescents, as well as representatives of secondary professional and higher education organizations to develop effective measures of career guidance in relation to applicants.

Key words: gifted youth, professional self-determination, representatives of working youth, self-realization, competitiveness.

ИССЛЕДОВАНИЕ ОСОБЕННОСТЕЙ

ПРОФЕССИОНАЛЬНОГО САМООПРЕДЕЛЕНИЯ ОДАРЕННОЙ МОЛОДЕЖИ (НА ПРИМЕРЕ РАБОТАЮЩЕЙ МОЛОДЕЖИ ТЮМЕНСКОЙ ОБЛАСТИ) ${ }^{1}$

\author{
Людмила Владимировна Гуляева \\ Тюменский государственный университет, г. Тюмень, Российская Федерация
}




\section{Галина Зиновьевна Ефимова}

Тюменский государственный университет, г. Тюмень, Российская Федерация

Аннотация. Представители одаренной молодежи являются стратегическим интеллектуальным ресурсом развития для всех стран в долгосрочной перспективе. Приоритетным направлением деятельности в отношении формирования творческого потенциала представителей одаренной молодежи является создание условий для актуализации их творческих способностей и интересов в ходе профессионального самоопределения.

Целью представленного теоретико-прикладного исследования является изучение факторов, влияющих на профессиональное самоопределение представителей одаренной молодежи, а также выявление наиболее существенных особенностей данного процесса.

Проанализированы результаты теоретических работ отечественных и зарубежных исследователей; проведен анализ официальных статистических данных. Методическую основу исследования составил анкетный опрос 956 представителей работающей молодежи, проведенный в 2017 г. в городах Тюмень, Тобольск и Ишим. Для анализа эмпирических данных использовалась лицензионная версия программы IBM SPSS Statistics 23.

Установлено, что наличие у молодежи высоких способностей в какой-либо сфере во время обучения в школе и в учреждениях среднего профессионального и высшего образования в дальнейшем способствует выбору ими работы по профилю полученного образования, а также более высокой оценке своего личностного и конкурентного потенциала, профессиональной компетентности. При этом респонденты из данной группы выражают более высокую заинтересованность переездом в другую страну, несмотря на обеспокоенность будущим России. Подтверждено предположение о том, что наличие у респондентов более высоких способностей в определенной области способствует более активному процессу их профессионального самоопределения, большей устойчивости и глубине их профессиональных интересов в избранной сфере деятельности.

Полученные в ходе исследования выводы могут быть полезны педагогам и психологам, осуществляющим профориентационную деятельность в рамках работы с одаренными детьми и подростками, а также представителям организаций среднего профессионального и высшего образования для разработки эффективных мероприятий профориентационной направленности в отношении абитуриентов.

Ключевые слова: одаренная молодежь, профессиональное самоопределение, представители работающей молодежи, самореализация, конкурентоспособность.

\section{Введение}

Одаренная молодежь - важнейший интеллектуальный ресурс, во многом определяющий вектор инновационного развития страны. В условиях современной высокотехнологичной экономики ориентации на наукоемкие отрасли производства приоритетными являются инвестиции в сферу образования, поскольку они способствуют формированию национального человеческого капитала. В Концепции общенациональной системы выявления и развития молодых талантов отмечается, что «современная экономика все больше нуждается в специалистах, обладающих глубокими знаниями и способных к новаторству, поэтому работа по выявлению и развитию молодых талантов, основанная на лучшем историческом опыте и наиболее успешных современных образцах, - необходимый элемент модернизации экономики России» [Концепция об- щенациональной системы... web]. Содействие актуализации данного потенциала будет способствовать формированию специалистов, способных ответить на инновационные вызовы современности, готовых к разработке и освоению новых производственных технологий.

В то же время острой остается проблема реализации творческого потенциала молодежи, поскольку не всегда выдающиеся способности находят применение в социальной практике. При данных обстоятельствах особую актуальность приобретает вопрос профессионального самоопределения талантливых юношей и девушек, так как именно оно является одним из ключевых факторов развития личности, создающим предпосылки для процесса самореализации и оказывающим определяющее влияние на общий процесс интеграции молодежи в систему социальных отношений после окончания учебы. Успешный выбор профессиональной деятельности являет- 
ся важным условием для наиболее полной реализации способностей молодежи в той области, которая представляет для них наибольший интерес.

Стремление личности к максимальной самореализации отражает одно из направлений более широких культурных процессов, происходящих в современных развитых обществах. Р. Инглегарт охарактеризовал эти изменения как «переход от материалистических ценностей к постматериалистическим», подчеркивая, что именно молодежь оказывается наиболее восприимчивой к ним. В результате происходящих изменений люди уделяют больше внимания качеству жизни и вопросам самовыражения, поскольку «усилия человека все меньше оказываются сосредоточенными на производстве материальных товаров, вместо этого акцент делается на коммуникации и на обработке информации, а в качестве важнейшей продукции выступают инновации и знания» [Инглегарт web].

Сложность рассмотрения понятия «одаренность» заключается прежде всего в том, что это многоаспектный феномен, проявляющийся в разных сферах человеческой деятельности - научной, художественной, спортивной, коммуникационной и др. По причине разнообразия форм и особенностей проявления одаренности исследователями не выработано единого общепринятого определения данного явления, вследствие чего часто такие характеристики, как «одаренные», «талантливые», «проявляющие высокие способности» и другие, близкие по смыслу, используются исследователями как синонимичные. В качестве наиболее распространенного базового понятия отечественными учеными используется определение, предложенное Д.Б. Богоявленской в «Рабочей концепции одаренности»: «Одаренность - системное, развивающееся в течение жизни качество психики, которое определяет возможность достижения человеком более высоких, незаурядных результатов в одном или нескольких видах деятельности по сравнению с другими людьми», оно понимается как «интегральное проявление разных способностей в целях конкретной деятельности» [Богоявленская 2004, 47-50]. Сложность изучения данного феномена связана в первую очередь с неустойчивой и ди- намичной природой одаренности. Внешние проявления одаренности (способности, ускоряющей интеллектуальное развитие) не являются неизменной, стабильной характеристикой, поскольку из-за особенностей индивидуального развития они могут как увеличиваться под влиянием благоприятных факторов (наличие соответствующей образовательной среды, грамотного воздействия педагогов и наставников), так и снижаться (если данное воздействие отсутствует или имеет негативный характер).

\section{Обзор литературы}

Феномен одаренности рассматривается в работах отечественных (А.Г. Асмолова, Ю.Д. Бабаевой, В.Н. Дружинина, Н.С. Лейтес, А.М. Матюшкина, В.И. Панова, М.А. Холодной, В.Д. Шадрикова, В.С. Юркевич) и зарубежных исследователей (Ф. Монкс, П. Торранса, К. Хеллера, Д. Фельдхьюсен и др.). Авторы акцентируют внимание на различных аспектах изучения одаренности, а также способах раскрытия творческих способностей личности, отмечая их зависимость от воздействия социальных условий.

В настоящее время одной из наиболее распространенных концепций одаренности является теория Дж. Рензулли, представляющая одаренность в качестве трехкольцевой модели. Последняя включает в себя общие или специальные способности выше среднего, высокий уровень включенности в задачу и высокий уровень креативности. Полагаем, что ни одна из приведенных характеристик в отдельности не является достаточным показателем одаренности, но только процесс взаимодействия между ними создает предпосылки для проявления творческой активности. Данная концепция предполагает, что к числу одаренных может быть отнесено значительно большее количество детей, чем тот небольшой процент учащихся, который обычно выявляют при помощи высоких оценок. Предложенная авторами «модель обогащенного школьного обучения» представляет собой систему специальных методов для стимулирования деятельности учеников, способствующую интеграции большого объема учебных навыков деятельности в разных 
областях школьной программы [Богоявленская 1997, 214-241]. Идеи, предложенные Дж. Рензулли, позднее легли в основу других концепций - модели одаренности Р. Стернберга и Е. Григоренко, «Пятифакторной модели» А. Танненбаума, а также ряда других теорий.

Исследователи M.-С. McClain и S. Pfeiffer отмечают, что высокий уровень интеллектуального развития лишь частично объясняет долгосрочный академический успех одаренных подростков, поскольку большую роль в процессе реализации личного потенциала одаренных молодых людей играют также такие факторы, как личные навыки, высокая мотивация, увлеченность определенным видом деятельности, настойчивость, уверенность в себе. Ученые подчеркивают, что развитие талантов является непрерывным индивидуальным процессом, поскольку не каждый ребенок, одаренный в раннем возрасте, следует общей траектории в своем развитии [McClain, Pfeiffer 2012, 78-79].

Существенный интерес в связи с рассматриваемой нами темой представляет модель структуры одаренности R.M. Milgram и E. Hong, которые занимались вопросами прогнозирования профессионального выбора одаренных детей. Исследователями проанализирована зависимость между творческим мышлением, креативной внешкольной активностью и индексом реальных достижений взрослых в их профессиональной, академической, общественной и других областях деятельности. Результаты исследования свидетельствовали о том, что высокие школьные оценки предсказывали достижения только в академической области, индекс интеллектуального развития достоверно не предсказывал достижений ни в одной конкретной области, а измерения творческой активности соотносились с достижениями взрослых в нескольких областях так же, как и внешкольная деятельность, как сфера проявления интеллектуальной и творческой активности. Таким образом, «креативность» рассматривается авторами как наиболее достоверная характеристика будущих жизненных достижений, чем индекс IQ и школьные оценки [Milgram, Hong 1993, 135-139].

В вопросе поддержки и развития одаренной молодежи важнейшей задачей является содействие реализации творческого потен- циала подростков после окончания их учебы, обеспечение условий, при которых высокий уровень развития способностей молодых людей и девушек в какой-либо сфере был бы востребован и актуализирован в дальнейшем в рамках их будущей профессиональной деятельности, другими словами, необходимо содействие их профессиональному самоопределению. Профессиональное самоопределение представляет собой важнейший этап личностного становления, поскольку создает основу для реализации творческих возможностей человека, обретения подлинной социальной зрелости, основанной на оценке собственных возможностей и соотнесении их с жизненными целями и приоритетами личностного развития подростков.

Наиболее точно, по нашему мнению, специфика профессионального самоопределения старшеклассников раскрыта в исследовании В.И. Шаповалова, рассматривающего данное явление как основанный на познании своих возможностей осознанный «выбор человеком той сферы профессиональной деятельности, в которой он может наилучшим образом реализовать свой личностный конкурентный потенциал в гармонии с потребностями общества» [Шаповалов 2008, 71]. В широком смысле профессиональное самоопределение можно рассматривать как одно из направлений процесса социализации, поскольку освоение профессии предполагает взаимодействие с различными социальными группами и позволяет человеку занять определенную позицию в иерархической структуре общества. При этом существенную особенность данного процесса отмечает в своем исследовании Е. Kaemmerer, подчеркивающий, что профессиональное самоопределение не является одномоментным событием, ограниченным во времени, а представляет собой часть непрерывного процесса формирования личностью собственной идентичности и не исключает возможности изменения профессии в дальнейшем, расширения сферы интересов, получения альтернативного образования [Kaemmerer 2011, 10].

Специфика профессионального самоопределения одаренных юношей и девушек определяется прежде всего их личными особенностями, склонностями, теми наиболее инте- 
ресными для них сферами деятельности, в которых они добиваются максимальных для своего возраста результатов (независимо от того, идет ли речь о спортивных достижениях, проявлении художественных способностей или, например, способностей в области точных наук). У одаренных подростков осознание своих склонностей, как правило, происходит более активно и подкрепляется высокими оценками их достижений со стороны родителей, учителей, наставников. Более высокие результаты в какой-либо деятельности по сравнению с результатами сверстников, а также субъективная легкость решения поставленных задач в определенной области побуждают таких подростков постоянно совершенствовать имеющиеся навыки, проявлять инициативу, пытаться решить поставленные задачи разными способами. В результате того, что занятие любимым делом дарит положительные эмоции, представляется более интересным и увлекательным по сравнению с другими занятиями, мотив деятельности постоянно подкрепляется и постепенно возникает устойчивый интерес к определенному виду деятельности, который поддерживается и в ходе образовательного процесса.

Исследования, посвященные изучению этапов профессионального развития, показали, что профессиональная творческая продуктивность связана с возрастом человека. Она постепенно увеличивается с начала карьеры, достигает максимума, а затем постепенно убывает. При этом отмечается, что творческие успехи достигают своего пика значительно позже, чем интеллектуальные способности человека. Американские исследователи H.C. Lehman, а позднее D.K. Simonton пришли к выводу, что несовпадение динамики творческих достижений и динамики развития способностей говорит о том, что между способностями и достижениями лежит большая, проделываемая человеком работа, в ходе которой он сам формируется как творец, анализируя свои способности, интересы, наиболее продуктивные формы социальной деятельности [Simonton 1997, 66-89].

Пытаясь проанализировать динамику творческого становления человека, американский исследователь психологии творчества Д. Симонтон предлагает использовать с этой целью двухэтапную модель данного процесса. Первый этап, по его мнению, связан с формированием и накоплением новых идей «идеацией» - и приходится на период юности. Второй этап предполагает преобразование идей в «коммуникативные конфигурации» и последующую разработку научных концепций, написание художественных произведений, разработку теорий. Д. Симонтон полагает, что скорость этого преобразования напрямую зависит от числа накопленных идей и с возрастом имеет тенденцию к снижению, что подтверждается приведенными исследователем эмпирическими данными [Ушаков 2011, 367368]. Как отмечает исследователь, когнитивные исследования творческой производительности должны сочетаться с исследованиями индивидуальных различий.

В то же время важно учитывать, что с одаренностью как сложным социально-психологическим феноменом связаны как благоприятные факторы, способствующие более активному интеллектуальному развитию талантливых детей и подростков, так и ряд особенностей их личностного развития, нередко создающих сложности в процессе социализации одаренной молодежи. К ним многие специалисты относят эмоциональные сложности, часто проявляющиеся в склонности к интровертности, сосредоточенности на собственных интересах и увлечениях, нетерпимости к мнению сверстников, сложности найти с ними общий язык. Еще одной распространенной проблемой признано недостаточное развитие волевых качеств, связанное с увлеченностью решением определенных задач в конкретной сфере, в которой деятельность наиболее интересна и результативна и, как следствие, избеганием видов деятельности, в которых приходится прилагать большие усилия в других вопpocax, а также трудности в восприятии критики.

Кроме того, анализируя вопросы взаимосвязи одаренности и жизненной самореализации, Д.В. Ушаков отмечает, что чрезмерно ранняя профессионализация ведет к сужению интересов и препятствует формированию полноценной личности. Дополнительную сложность проблеме одаренных детей придает тот факт, что выдающиеся достижения детей обеспечиваются структурой способностей, отличающейся от выдающихся достижений 
взрослых [Ушаков 2011, 366]. В.С. Юркевич отмечает такие проблемы, как значительное отставание потребности в общении от познавательной, низкая толерантность к неопределенности, проблемы эмоциональной регуляции [Юркевич 2010, 118-129].

Перечисленные факторы могут негативно отражаться на личностном развитии подростков, выстраивании отношений с окружающими, когда человеку приходится самостоятельно принимать решения, взаимодействовать с представителями разных групп, отстаивать свои интересы в ходе конкурентных взаимодействий, разрешать конфликтные ситуации и находить компромиссные варианты.

Исходя из данных обстоятельств можно сформулировать следующие, наиболее значимые условия успешного профессионального самоопределения одаренной молодежи:

1. Поддержание и развитие высокой мотивированности деятельности поскольку, как отмечает Д.Б. Богоявленская, внутренняя мотивация является системообразующим компонентом одаренности, позволяющим достигать высоких результатов и творчески решать поставленные задачи [Богоявленская 2004, 52-60].

2. Необходимым условием профессионального самоопределения является вовлеченность талантливых подростков в исследовательскую работу, поскольку для формирования творческих способностей важным является включение личности в творческий процесс. Кроме того, специалисты отмечают, что исследовательская деятельность обеспечивает более высокий уровень системности знания, исключающий формальный характер его передачи в ходе учебного процесса.

3. Необходимым условием является формирование системы ценностей, которые отражали бы гуманистические представления, этические принципы деятельности, моральные нормативы.

Важно отметить, что профессиональное самоопределение современной молодежи происходит в условиях, когда ситуация на рынке труда отличается высокой динамичностью происходящих изменений. Появляются новые виды деятельности и соответствующие им формы занятости, при этом выпус- кникам часто сложно оценить, насколько перспективными они окажутся в будущем. Расширение сферы выбора профессиональной деятельности для современной молодежи, с одной стороны, позволяет молодым людям и девушкам найти тот вид деятельности, который бы в наибольшей степени соответствовал их интересам и склонностям, с другой увеличивает личную ответственность за совершенный выбор в ситуации, когда последствия многих происходящих изменений сложно предсказать. Оценивая современное общество как «общество риска», У. Бэк отмечает, что для него характерно «разрушение рамок специализированных компетенций», когда происходит индивидуализация социального неравенства, отражающаяся и на профессиональной деятельности. В этих условиях люди начинают в большей мере зависеть от самих себя и своей индивидуальной судьбы на рынке труда с ее шансами и противоречиями, полученная профессия перестает быть «объективной гарантией» и появляется необходимость в индивидуальной карьерной ориентации [Бек 2000, 65-74].

Содействие вопросам выявления, поддержки, а также профессионального самоопределения талантливой молодежи является одним из приоритетных направлений развития нашего государства. В Концепции общенациональной системы выявления и развития молодых талантов отмечается, что в условиях изменчивой и конкурентной экономики приоритетной становится «задача обеспечения "социального лифта" для талантливой молодежи» [Концепция общенациональной системы... web]. В России постепенно формируется широкая система поддержки одаренной молодежи, ориентированная на работу с детьми и подростками, проживающими как в городах, так и в сельской местности, формируются региональные и общероссийские базы талантливых детей и молодежи. С этой целью в нашей стране реализуется целый ряд проектов, направленных на то, чтобы расширить перспективы профессионального выбора для наиболее способной и творчески активной молодежи. Активно занимается поддержкой одаренных детей и подростков Образовательный центр «Сириус» (Сочи), ориентирующийся на раннее выявление и развитие детей, проявивших выдающие- 
ся способности в области науки, техническом творчестве, искусстве. К числу основных задач деятельности «Сириуса» его создатели относят охват максимального количества одаренных российских школьников и их педагогов, содействие повышению уровня профессиональной подготовки во всех субъектах Российской Федерации, развитие условий для реализации интеллектуального потенциала и профессионального самоопределения детей, независимо от их места жительства и социального положения. Образовательный центр «Сириус» сотрудничает с 32 субъектами России, включая Тюменскую область [Образовательный центр «Сириус» web].

К числу наиболее значимых проектов, направленных на поддержку творческой молодежи, можно отнести открытую платформу «Россия - страна возможностей», которая объединяет мероприятия, направленные на самореализацию талантливой молодежи в разных сферах деятельности, включающую такие самостоятельные проекты, как «Я - профессионал» - национальную олимпиаду для студентов по 27 профессиональным направлениям; организация портала для поиска практики и стажировок по инженерно-техническим специальностям «Профстажировки»; регулярное проведение чемпионатов по профессиональному мастерству среди молодых специалистов «Молодые профессионалы» (WorldSkills Russia); организация информационного ресурса для предпринимателей «Бизнес-навигатор МСП» и другие проекты [Форум... web].

Еще одним направлением деятельности по поддержке профессионального становления одаренной молодежи является создание технопарков «Кванториум», ориентированных на привлечение детей и молодежи к изучению и практическому применению наукоемких технологий; подготовку высококвалифицированных инженерных кадров, разработку, тестирование и внедрение инновационных технологий и идей [Детский технопарк «Кванториум» web]. Так, с целью содействия техническому развитию молодежи в 2017 г. в Тюмени открылся детский технопарк «Кванториум», в котором дети и подростки обучаются по направлениям «Робоквантум», «Промышленный дизайн», «ІТ-квантум», «Аэроквантум», «Автоквантум».
В рамках государственной программы Тюменской области «Развитие образования и науки» до 2020 г. по направлению работы с одаренными детьми и талантливой молодежью реализуются мероприятия областного проекта «Стратегия успеха», разработанного на основе межуровневого взаимодействия (учреждения дошкольного, общего, профессионального образования) [Государственная программа... web]. Между Образовательным Фондом «Талант и успех», Правительством Тюменской области и Тюменским государственным университетом подписано Соглашение по развитию интеллектуального потенциала молодежи, включающее создание Регионального центра выявления и поддержки одаренных детей в области науки.

В Тюменской области также уделяется большое внимание вопросам выявления талантливых детей и подростков и создания благоприятных условий для раскрытия их творческого потенциала. На территории Тюменской области действует Закон Тюменской области от 06.02.1997 № 72 «О молодежной политике в Тюменской области». В нем подчеркивается, что, учитывая особое общественное значение одаренной личности, в регионе осуществляются меры по созданию наиболее приемлемых условий для творческой деятельности молодежи, целью которых является сохранение и развитие интеллектуального и творческого потенциала. В рамках реализации данных задач в Тюменской области действует Региональный центр развития и поддержки одаренных детей, ориентированный на выявление среди учащихся талантливых детей и создание условий для их развития [Закон Тюменской области от 06.02.1997... web].

С целью содействия профессиональному самоопределению талантливой молодежи в Тюменской области проводятся такие мероприятия, как областной чемпионат по робототехнике и программированию на кубок Губернатора Тюменской области; конкурс «JuniorSkills»» для учащихся 10-17 лет в рамках чемпионата WorldSkills; конкурс молодежных проектов в рамках форума молодежи Уральского федерального округа «УТРО»; Всероссийский конкурс молодежных проектов (Росмолодежь) и другие мероприятия [Поддержка талантливых детей... web]. 
В 2017 г. в Тюменской области проведены федеральные конкурсы, ориентированные на поддержку талантливой молодежи: Всероссийский конкурс детского и юношеского творчества «Роза ветров в Тюмени»; Всероссийская культурно-просветительская акция для одаренных детей «Всероссийский фестиваль юных художников "Уникум"»; Региональный отбор на XVI Молодежные Дельфийские игры России; III Межрегиональный химический турнир 2017 г., организуемый Факультетом наук о материалах и химическим факультетом Московского государственного университета имени М.В. Ломоносова и Национальным центром непрерывного естественнонаучного образования. Среди региональных конкурсов для одаренной молодежи, проведенных в 2017 г. в Тюменской области: Областной чемпионат по робототехнике и программированию на Кубок Губернатора Тюменской области; $\mathrm{XX}$ областной научный форум молодых исследователей «Шаг в будущее»; IV Открытый Региональный чемпионат «Молодые профессионалы» (WorldSkills Russia) Тюменская область; Региональный робототехнический фестиваль «РобоФест Тюмень»; Областной открытый конкурс молодых дарований «Дебют 2017».

\section{Материалы и методы}

В процессе работы над статьей отмечено несколько существующих проблем: недостаток теоретико-прикладных исследований, посвященных изучению особенностей профессионального самоопределения одаренной молодежи; недостаточная изученность влияния одаренности на такие аспекты жизни молодежи, как трудоустройство в соответствии с полученной специальностью; реализация одаренности в условиях конкуренции; наличие / отсутствие желания переехать в другую страну.

Цель проведенного исследования - изучение влияния высокого уровня развития способностей, проявленных представителями работающей молодежи во время учебы на такие аспекты профессионального самоопределения, как уровень удовлетворенности своей профессией, оценка своего личностного потенциала.

Выбор для изучения представителей работающей молодежи связан в первую очередь с тем, что имеющийся у данной социально-демографической группы опыт профессиональной деятельности позволяет наиболее полно и достоверно оценить, насколько их интересы и склонности, сформированные в период обучения, реализовались в их профессиональной деятельности. В то время как школьники и студенты в большинстве случаев еще не имеют подобного опыта, либо он чрезвычайно ограничен. Рабочая гипотеза проведенного социологического исследования предполагает наличие взаимосвязи между наличием у респондентов высокого уровня развития способностей, проявленных во время учебы, и процессом профессионального самоопределения, выражающейся в удовлетворенности профессиональным выбором, преимущественном соответствии работы, полученной во время учебы специальности; а также высокой самооценки уровня конкурентоспособности на рынке труда.

Коллективом социологической лаборатории кафедры общей и экономической социологии Тюменского государственного университета в период с марта по июнь 2017 г. проведено исследование уровня конкурентоориентированности и конкурентоспособности современной молодежи. Эмпирическую базу исследования составили данные анкетирования 956 представителей работающей молодежи в городах юга Тюменской области: Тюмень (711 человек), Тобольск (169 человек), Ишим (76 человек). Опрос проведен по месту работы респондентов - в двадцати организациях основных отраслей экономики. Метод исследования - анкетный опрос. Тип выборки: квотная, районированная, гнездовая. Репрезентативность определялась по признакам: пол, возраст и среднемесячная заработная плата работников, форма собственности предприятия (организации), отрасль экономики. Для анализа полученных данных использовалась программа IBM SPSS Statistics 23.

\section{Результаты исследования}

Участие в олимпиадах по учебным предметам во время обучения в школах, учреждениях среднего профессионального и высшего образования можно рассматривать в качестве объективного индикатора наличия углубленных знаний и высоких способ- 
ностей респондента в конкретной области. В среднем по выборке в олимпиадах принимали участие $55 \%$ респондентов. В дополнение к данному индикатору рассмотрим уровень олимпиад: победа в олимпиадах регионального уровня и продолжение борьбы на мероприятиях федерального или же международного уровня являются показателем формирующегося личного конкурентного потенциала молодежи. Наибольшее количество участников олимпиад приходится на общеобразовательные учреждения - суммарно $44 \%$, во время обучения в техникумах и колледжах принимали участие в олимпиадах $14 \%$ и в вузах - $22 \%$ (табл. 1).

Для оценки уровня конкурентоспособности работающей молодежи в анкету включен вопрос «Считаете ли вы себя конкурентоспособным?». В среднем по выборке конкурентоспособными считают себя более половины опрошенных представителей работающей молодежи - $57 \%$, еще $33 \%$ воспринимают себя скорее конкурентоспособными, в то время как скореенеконкурентоспособными или же совершенно неконкурентоспособными оценивают себя лишь $10 \%$. Полученные данные свидетельствуют о достаточно высокой оценке респондентами своих личных возможностей. Среди ныне конкурентоспособных респондентов 58 \% принимали участие в олимпиадах по учебным предметам, а их неконкурентоспособные (по самооценке) ровесники - в 1,3 раза реже (44 \%).

Респонденты, принимавшие участие в олимпиадах по учебным предметам, в $74 \%$ случаев имеют высшее и послевузовское образование, а среди не принимавших участие лишь $57 \%$.

Еще одним индикатором профессиональной успешности и готовности молодых работников продемонстрировать конкурентоспособ- ность в прикладной деятельности становится участие в профессиональных конкурсах и соревнованиях. В среднем по выборке в подобных конкурсах профессионального мастерства участвовали лишь 7 \% респондентов. Обратимся к таблицам сопряженности данной переменной с другими, проанализированными нами ранее.

Респонденты, участвовавшие в конкурсах профессионального мастерства, в 75 \% случаев принимали участие в олимпиадах различного уровня во время обучения в школе и учреждениях профессионального образования. В то же время их ровесники, не желающие испытать свой профессиональный уровень в рамках соответствующих профессиональных конкурсов, были участниками олимпиад лишь в каждом четвертом случае (25\%). Корреляция между данными дихотомическими переменными составила 0,320 (по Спирману), что свидетельствует о слабой связи между переменными на высоком уровне значимости (корреляция значима на уровне 0,01 , двухсторонняя).

Полученные данные подтверждают наличие взаимосвязи между сформированным в период обучения углубленным познавательным интересом в определенной сфере, высокой оценкой личного конкурентного потенциала и, как следствие, профессиональной состоятельности и способности отстаивать свои интересы в ходе конкурентного взаимодействия.

Следующий рассматриваемый нами аналитический блок касается вопроса «Является ли сделанный вами выбор профессии окончательным?». Среди опрошенных представителей работающей молодежи каждый третий считает выбор профессии окончательным (33\%), чуть меньше доля тех, кто не считает выбор своей профессии завершенным (32 \%),

Таблица 1

Распределение ответов респондентов на вопрос «Если Вы участвовали в олимпиадах во время обучения, то укажите уровень олимпиады» (в \% к числу опрошенных)

\begin{tabular}{|l|c|c|c|}
\hline \multicolumn{1}{|c|}{ Вариант ответа } & В школе & В техникуме & В вузе \\
\hline На уровне учебного заведения & 13,7 & 6,0 & 12,4 \\
\hline На уровне города, района & 19,7 & 5,2 & 4,7 \\
\hline На уровне региона & 8,1 & 2,1 & 2,6 \\
\hline На уровне Федерального округа & 1,6 & 0,7 & 1,2 \\
\hline На уровне Российской Федерации & 0,9 & 0,3 & 1,0 \\
\hline Не участвовал(а) & 56,0 & 85,7 & 78,1 \\
\hline \multicolumn{1}{r|}{ Итого } & 100,0 & 100,0 & 100,0 \\
\hline
\end{tabular}




\section{СОЦИОЛОГИЯ И СОЦИАЛЬНЫЕ ТЕХНОЛОГИИ}

и более трети выборки составляют те, кто не смог определиться в этом вопросе (35\%).

При этом среди респондентов, считающих свой профессиональный выбор окончательным, больше половины опрошенных (59\%) во время обучения принимали участие в олимпиадах по учебным предметам, в то время как тех, кто в них не участвовал, оказался лишь 41 \%, что подтверждает предположение о том, что наличие у респондентов более высоких способностей в определенной области способствует более активному процессу их профессионального самоопределения, большей устойчивости и глубине их профессиональных интересов.

Респонденты, участвующие в конкурсах профессионального мастерства, чаще отмечают, что нынешний выбор профессии для них окончательный (46 \%). В то же время не участвующие в подобных конкурсах отрицают стабильность профессионального выбора или же сомневаются в нем - соответственно в $31 \%$ и $25 \%$ случаев (табл. 2).

Не отмечено статистически значимой связи между рассматриваемой переменной («Является ли сделанный вами выбор профессии окончательным?») и участием в олимпиадах в школьном и студенческом возрасте.

Важным показателем процесса профессионального самоопределения молодежи является то, соответствует ли имеющаяся у участников опроса работа по специальности, полученной ими в профессиональном учебном заведении. Соответствие своей работы полученной во время учебы специальности, отметили $39 \%$ респондентов, примерно столько же $(40 \%)$ заявили об их частичном соответствии, в то время как пятая часть участников исследования (21 \%) отметила их полное несоответствие. Следует подчеркнуть, что среди группы респондентов, чья работа соответствует профилю обучения, больше тех, кто участвовал во время учебы в олимпиадах (41\%) по сравнению с теми, кто в них не участвовал (35\%), что отражает положительное влияние сформированных профессиональных интересов на последующее трудоустройство с учетом избранного профиля деятельности.

В отношении удовлетворенности участников исследования своей профессией не выявлено существенных различий в ответах представителей данных групп, поскольку абсолютное большинство опрошенных представителей работающей молодежи (как тех, кто во время учебы участвовал в олимпиадах (84\%), так и тех, кто в них не участвовал $(83 \%))$ отмечают, что их профессия им нравится, лишь $14 \%$ опрошенных как в той, так и в другой группе, по их словам, относятся к ней безразлично или она им не нравится.

На вопрос, участвовали ли опрошенные в каких-либо профессиональных соревнованиях и конкурсах (например, на лучшего молодого рабочего), абсолютное большинство (93\%) ответили, что не участвовали.

Две трети опрошенной работающей молодежи имеют высшее и послевузовское образование $(67 \%)$, каждый шестой окончил учреждения среднего профессионального образования (16\%), незаконченное высшее профессиональное образование у $8 \%$, суммарно $9 \%$ имеют неполное среднее, среднее общее и начальное профессиональное образование.

Таблица 2

\section{Распределение ответов респондентов на вопрос}

«Считаете ли Вы выбор профессии окончательным?» в зависимости от ответа на вопрос «Участвовали ли Вы в профессиональных соревнованиях и конкурсах молодого рабочего?» (в \% от общего числа опрошенных)

\begin{tabular}{|c|c|c|c|}
\hline & \multicolumn{2}{|c|}{$\begin{array}{c}\text { Участвовали ли Вы в профессиональных сорев- } \\
\text { нованиях и конкурсах молодого рабочего? }\end{array}$} \\
\hline & & Да, участвовал & Нет, не участвовал \\
\hline \multirow{3}{*}{$\begin{array}{l}\text { Считаете ли Вы выбор про- } \\
\text { фессии окончательным? }\end{array}$} & Да & 45,9 & 32,1 \\
\hline & Нет & 31,1 & 31,4 \\
\hline & $\begin{array}{l}\mathrm{He} \\
\text { знаю }\end{array}$ & 23,0 & 36,5 \\
\hline \multicolumn{2}{|r|}{ Итого } & 100,0 & 100,0 \\
\hline
\end{tabular}


Основную часть опрошенных представителей работающей молодежи беспокоит (72 \%) или скорее беспокоит (25\%) будущее России. Респондентов, состоящих в официальном браке, будущее страны беспокоит несколько больше (75\%), чем участников исследования, пока не имеющих собственных семей $(70 \%)$, или тех, кто находится в официально не зарегистрированных отношениях (68 \%) [Гуляева, Ефимова 2018, 64-65]. На вопрос «Хотели бы Вы уехать из России?» примерно половина опрошенных из данной группы (49 \%) ответила отрицательно, еще $25 \%$ - «скорее не хотели бы», в то время как лишь $16 \%$ допускают такую возможность с большей или меньшей степенью вероятности.

На основании ключевых результатов проведенного нами социологического исследования можно сделать следующие выводы, связанные с особенностями профессионального самоопределения работающей молодежи:

1. Респонденты, проявлявшие во время учебы в школе и профессиональном учебном заведении высокие способности и принимавшие участие в предметных олимпиадах, в большей мере склонны характеризовать сделанный профессиональный выбор как окончательный. Соответственно, им не свойственны «метания» от одной профессиональной стези к другой и готовы к целостной самореализации в рамках выбранной профессиональной траектории с целью повышения собственного профессионализма и укрепления конкурентных преимуществ. Можно сделать вывод, что наличие у респондентов высоких способностей в какой-либо области создает благоприятные условия для их профессионального самоопределения, поскольку содействует углублению и расширению знаний в сфере деятельности, соответствующей их интересам, а также постепенной выработке необходимых качеств в соответствии с требованиями, предъявляемыми профессией.

2. Респонденты, проявлявшие во время учебы высокие способности в какой-либо области, чаще работают по профилю полученного образования, предположительно в силу того, что их познавательные интересы в значительной мере соответствуют профессиональным, а навыки, приобретенные во время учебы, актуализируются и расширяются в ходе профессиональной деятельности.

3. Работающая молодежь, участвовавшая во время обучения в школе и учреждениях среднего профессионального и высшего образования в предметных олимпиадах, проявляет несколько большую заинтересованность в отношении планов переезда в другую страну, что, вероятно, связано с более высокой оценкой ими личного конкурентного потенциала и большей уверенностью в востребованности своих профессиональных навыков.

4. В целом группа респондентов, демонстрировавших в период обучения в школе и профессиональных учебных заведениях значительные успехи, выше оценивает личный потенциал и более уверенно называет себя конкурентоспособными по сравнению с остальными респондентами. Таким образом, нашла подтверждение выдвинутая нами исследовательская гипотеза о наличии у респондентов более высоких способностей в какойлибо области и несколько большей глубиной и устойчивостью процесса профессионального самоопределения.

\section{ПРИМЕЧАНИЕ}

${ }^{1}$ Исследование выполнено при финансовой поддержке государственного задания Минобрнауки РФ в рамках проекта № 28.2941.2017/4.6 «Формирование конкурентоориентированности и конкурентоспособности молодежи в российском обществе в контексте современной социокультурной динамики».

The study was supported by the State task of the Ministry of Education and Science of the Russian Federation within project no. 28.2941.2017/4.6 "Formation of Competitive Orientation and Competitiveness of Young People in the Russian Society in the Context of Modern Socio-Cultural Dynamics."

\section{СПИСОК ЛИТЕРАТУРЫ}

Бек 2000 - Бек У. Общество риска: на пути к другому модерну. М.: Прогресс-Традиция, 2000.

Богоявленская 1997 - Богоявленская Д.Б. Основные современные концепции творчества и одаренности. М.: Молодая гвардия, 1997. 
Богоявленская 2004 - Богоявленская Д.Б. Рабочая концепция одаренности // Вопросы образования. 2004. № 2. С. 46-68.

Государственная программа... web-Государственная программа Тюменской области «Развитие образования и науки» до 2020 и на плановый период до 2025 // https://admtyumen.ru/ogv_ru/finance/ programs/program.htm?id=1193@egTargetGrant.

Гуляева, Ефимова 2018 - Гуляева Л.В., Ефимова Г.З. Сравнительное исследование патриотических ориентаций молодежи: региональная специфика // Siberian Socium. 2018. T. 2, № 1. C. 5373. DOI: $10.21684 / 2587-84-2018-2-1-53-73$.

Детский технопарк «Кванториум» web - Детский технопарк «Кванториум»//http://kvantoriumtyumen.ru/kvantorium/about.

Закон Тюменской области от 06.02.1997... web - Закон Тюменской области от 06.02.1997 № 72 «О молодежной политике в Тюменской области» // http://docs.cntd.ru/document/802033016.

Инглегарт web - Инглегарт Р. Культурный сдвиг в зрелом индустриальном обществе [Новая постиндустриальная волна на Западе. Антология. 1999] // https://lib.uni-dubna.ru/search/files/ kult_nov_post_volna/8.htm.

Концепция общенациональной системы... web Концепция общенациональной системы выявления и развития молодых талантов [Комплекс мер по реализации Концепции общенациональной системы выявления и развития молодых талантов] // http://edu53.ru/npincludes/upload/2012/09/10/2837.pdf.

Образовательный центр «Сириус» web - Образовательный центр «Сириус» // https://sochisirius.ru /o-siriuse/obschaja-informatsija.

Поддержка талантливых детей... web - Поддержка талантливых детей и молодежи в Тюменской области // https://tyumedia.ru/212366.html.

Ушаков 2011 - Уиаков Д.В. Психология интеллекта и одаренности. М.: ИП РАН, 2011.

Форум... web - Форум «Россия - страна возможностей» объединил кадровую и интеллектуальную элиту страны // https://минобрнауки.рф/пресс-центр/12421.

Шаповалов 2008 - Шаповалов В.И. Формирование конкурентоспособности личности в условиях школьного дополнительного образования. Сочи: СГУТиКД, 2008.

Юркевич 2010 - Юркевич В.С. Современные проблемы работы с одаренными детьми // Психологическая наука и образование. 2010. № 5. C. $118-129$.

Kaemmerer 2011 - Kaemmerer E. Professional orientation - career pathways // Professional orientation, five steps to decision on school and occupation Elementary school professional orientation program. Belgrade: InDesigner, 2011. P. 8-11.

McClain, Pfeiffer 2012 - McClain M.-C., Pfeiffer S. Identification of Gifted Students in the United States Today: A Look at State Definitions, Policies, and Practices // Journal of Applied School Psychology. 2012. Vol. 28. P. 59-88. DOI: 10.1080/15377903.2012.643757.

Milgram, Hong 1993 - Milgram R. M., Hong E. Creative thinking and creative performance in adolescents as predictors of creative attainments in adults: A followup study after 18 years // Roeper Review. Iss. 3. Longitudinal Studies in Gifted Education. 1993. Vol. 15. P. 135-139. DOI: 10.1080/02783199309553487.

Simonton 1997 - Simonton D.K. Creative Productivity: A Predictive and Explanatory Model of Career Trajectories and Landmarks // Psychological Review. 1997. Vol. 104, № 1. P. 66-89.

\section{REFERENCES}

Bek U., 2000. Risk Society: towards another modernity. Moscow, Progress-Tradition Publ.

Bogojavlenskaja D.B., 1997. Basic modern concepts of creativity and giftedness. Moscow, Molodaja gvardija Publ.

Bogoyavlenskaya D.B., 2004. Working concept of giftedness. Voprosy obrazovaniya, no. 2, pp. 46-68.

The state program of the Tyumen region "Development of education and science" until 2020 and the planning period until 2025. URL: https:// admtyumen.ru/ogv_ru/finance/programs/ program.htm?id=1193@egTargetGrant (accessed 15 November 2018).

Gulyaeva L.V., Efimova G.Z., 2018. Comparative study of Patriotic orientations of youth: regional specificity. Siberian Socium, Vol. 2, no. 1, pp. 53-73. DOI: 10.21684/2587-84-2018-2-1-53-73.

Children's technology Park “Kvantorium”. URL: http:/ /kvantorium-tyumen.ru/kvantorium/about/ (accessed 10 November 2018).

Law of the Tyumen region of February 06, 1997 no. 72 "About youth policy in the Tyumen region". URL: http://docs.cntd.ru/document/802033016 (accessed 15 November 2018)

Inglhart R. Cultural shift in Mature industrial society. New post-industrial wave in the West. Anthology. 1999. URL: https://lib.uni-dubna.ru/search/files/ kult_nov_post_volna/8.htm (accessed 28 November 2018).

The concept of a nationwide system for the identification and development of young talents. 
A set of measures to implement the Concept of a national system for the identification and development of young talents. URL: http:// edu53.ru/np-includes/upload/2012/09/10/ 2837.pdf (accessed 18 November 2018).

Educational center "Sirius" General information. URL: https://sochisirius.ru/o-siriuse/obschajainformatsija (accessed 11 November 2018).

Support for talented children and youth in the Tyumen region. URL: https://tyumedia.ru/212366.html (accessed 10 November 2018).

Ushakov D.V., 2011. Psychology of intelligence and giftedness. Moscow, Publishing House "Institute of psychology RAS".

Forum "Russia - country of opportunities" brought together human and intellectual elite of the country. URL: https:/минобрнауки.pф/прессцентр/12421 (accessed 15 November 2018).

Shapovalov V.I., 2008. Formation of competitiveness of the individual in terms of additional school education. Sochi, SGUTiKD.

Yurkevich V.S., 2010. Modern problems of work with gifted children. Psihologicheskaya nauka $i$ obrazovanie, no. 5. URL: http://psyedu.ru/files/ articles/psyedu_ru_2010_5_1960.pdf(accessed 6 November 2018) .

Kaemmerer E., 2011. Professional orientation - career pathways. Professional orientation Five steps to decision on a school and occupation Professional orientation elementary school program. Belgrade, InDesigner, pp. 8-11.

McClain M.-C., Pfeiffer S., 2012. Identification of Gifted Students in the United States Today: A Look at State Definitions, Policies, and Practices. Journal of Applied School Psychology, Vol. 28, pp. 59-88. DOI: 10.1080/ 15377903.2012.643757.

Milgram R. M., Hong E., 1993. Creative thinking and creative performance in adolescents as predictors of creative attainments in adults: A followup study after 18 years. Roeper Review. Issue 3: Longitudinal Studies in Gifted Education, Vol. 15, pp. 135-139. DOI: 10.1080/ 02783199309553487.

Simonton D.K., 1997. Creative Productivity: A Predictive and Explanatory Model of Career Trajectories and Landmarks. Psychological Review, Vol. 104, no. 1, pp. 66-89.

\section{Information about the Authors}

Lyudmila V. Gulyaeva, Candidate of Sciences (Sociology), Senior Researcher, Sociological Research Laboratory, Department of General and Economic Sociology, Tyumen State University, Lenina St., 16, 625003 Tyumen, Russian Federation, lyudmila_gulyaeva_tmn@mail.ru, https://orcid.org/0000-0002-0463-4743

Galina Z. Efimova, Candidate of Sciences (Sociology), Associate Professor, Department of General and Economic Sociology, Tyumen State University, Lenina St., 16, 625003 Tyumen, Russian Federation, EfimovaGZ@gmail.com, https://orcid.org/0000-0002-4826-2259

\section{Информация об авторах}

Людмила Владимировна Гуляева, кандидат социологических наук, старший научный сотрудник учебно-научной социологической лаборатории при кафедре общей и экономической социологии, Тюменский государственный университет, ул. Ленина, 16, 625003 г. Тюмень, Российская Федерация, lyudmila_gulyaeva_tmn@mail.ru, https://orcid.org/0000-0002-0463-4743

Галина Зиновьевна Ефимова, кандидат социологических наук, доцент кафедры общей и экономической социологии, Тюменский государственный университет, ул. Ленина, 16, 625003 г. Тюмень, Российская Федерация, EfimovaGZ@gmail.com, https://orcid.org/0000-0002-4826-2259 